\title{
Surface characterization of eucalyptus and ash wood veneers by XPS, TOF-SIMS, optic profilometry and contact angle measurements
}

\author{
G. Vázquez, R. Ríos, M. S. Freire, G. Antorrena \\ \& J. González-Álvarez \\ Department of Chemical Engineering, \\ University of Santiago de Compostela, Spain
}

\begin{abstract}
Composition and properties of the wood surface are very important in board manufacture as they determine wood-adhesive bonding and the quality of the final product. In this work two spectroscopic techniques, X-ray photoelectron spectrometry (XPS) and time of flight secondary ion mass spectrometry (TOF SIMS), have been employed to study the surface composition of eucalyptus (Eucalyptus globulus) and ash (Fraxinus excelsior) sliced cut veneers. Both wood species are widely used for decorative veneers in the finishing of wood panels (particle boards, medium density fiber-boards, etc.). Further characterization of the wood surface was carried out by optic profilometry and wettability analysis, using the sessile drop method to measure contact angles. Wood is a very heterogeneous material and its composition can vary significantly depending on the sampling area; then, the influence of the radial position of the veneer in the trunk was also analyzed. From the low resolution XPS spectra the oxygen to carbon $(\mathrm{O} / \mathrm{C})$ ratio was calculated and, resolving the $\mathrm{C} 1 \mathrm{~s}$ signal, the percentages of the different carbon peaks corresponding to different functional groups $(\mathrm{C} 1, \mathrm{C} 2, \mathrm{C} 3$ and $\mathrm{C} 4$ carbons) were also calculated. The lower $\mathrm{O} / \mathrm{C}$ ratio and the higher $\mathrm{C} 1 / \mathrm{C} 2$ ratio for eucalyptus than for ash was attributed to the higher concentration of extractives on the eucalyptus wood surface that was confirmed by the TOF-SIMS spectra, which additionally revealed a patchy distribution of the extractives. The higher hydrophobicity of the eucalyptus wood surfaces was also supported by the results on the wetting properties of the veneers. Eucalyptus veneers exhibited a significantly higher constant wetting rate angle (cwra) and, consequently, a lower wettability than
\end{abstract}


ash veneers, which can also be related with the higher values of the rugosity parameters for the latter. There were no significant influences of the radial position of the veneer on the surface properties.

Keywords: wood veneers, wettability, contact angles, XPS, TOF-SIMS, optic profilometry.

\section{Introduction}

Wood is a renewable resource composed mainly of three polymers, cellulose, hemicelluloses and lignin, and various extractives such as fatty acids, sterols, tannins, etc. Wood surface characteristics condition the interaction with adhesives and binders in wood based products and, therefore, have influence in the quality of the final product. Several methods have been proposed to characterize material surfaces. Contact angle analysis is one the traditional methods for the characterization of surfaces on a macroscopic scale, and provides information on surface wetting properties [1].

Surface chemical composition of complex materials such as wood can be determined using two complementary spectroscopic techniques, X-ray photoelectron spectroscopy (XPS) and time-of-flight secondary ion mass spectrometry (TOF-SIMS), the former generating more quantitative data and the latter more qualitative data [2]. X-ray photoelectron spectroscopy (XPS) provides the elemental composition for the outermost 5-10 $\mathrm{nm}$ surface layers and functional groups, chemical bonding types, oxidation state, etc. can be additionally deduced from XPS data. Time-of-flight secondary ion mass spectrometry (TOF-SIMS) provides data for depths of 1-2 $\mathrm{nm}$, including detailed chemical information via identification of intact molecular ions or characteristic molecular fragments that are emitted from the surface [3]. Additionally, it provides ion images, mapping the lateral distribution of secondary ions signals from lignin, carbohydrates, extractives and metals within an analyzed wood surface area $[2,4]$.

The aim of this paper was to evaluate and compare the surface properties and composition of eucalyptus (Eucalyptus globulus) and ash (Fraxinus excelsior) sliced cut veneers used as decorative veneers in the finishing of wood panels. A wettability analysis, using the sessile drop method to measure contact angles, was applied in combination with two spectroscopic techniques, X-ray photoelectron spectrometry (XPS) and time of flight secondary ion mass spectrometry (TOF -SIMS). Roughness of the wood surface was analysed by optic profilometry. Wood is a very heterogeneous material and its composition can vary significantly depending on the sampling area; then, the influence of the radial position of the veneer in the trunk was also analyzed.

\section{Methods}

\subsection{Contact angle determination}

Samples of eucalyptus (Eucalyptus globulus) and ash (Fraxinus excelsior) sliced cut veneers with a humidity of $8 \%$ (wet basis) were used to prepare $2 \mathrm{~cm}$ (length) 
x $2 \mathrm{~cm}$ (width) x $0.6 \mathrm{~mm}$ (thickness) wood pieces. Contact angle measurements were made perpendicular to the grain direction of the wood according to the sessile drop method using a Dataphysics OCA 15 Plus equipment (Filderstadt, Germany) with a video measuring system with a high-resolution CCD camera. The data were analyzed with the Dataphysics software SCA 20.

To compare the wettability of both wood species and to analyze the influence of the radial position of the veneer in the trunk, $20 \%$ (by weight) aqueous solutions of chestnut shell extracts, potential components of wood adhesives [5], were used. Ten $\mu \mathrm{L}$ drops were added and the variation of contact angle with time was registered till $240 \mathrm{~s}$.

Contact angles were calculated according to the Young-Laplace method. The constant wetting rate angle (cwra) was determined as per Nussbaum [6] plotting the wetting rate ( $d \theta / \mathrm{dt}$, being $\theta$ the contact angle) against time and selecting the $\theta$ value (cwra) corresponding to a constant wetting rate. Initial $\left(\theta_{0}, t=0\right)$, final $\left(\theta_{\mathrm{f}}\right.$, $\mathrm{t}=240 \mathrm{~s})$ and cwra contact angles were calculated as the average of thirty measurements on each wood species and radial position.

\subsection{X-ray photoelectron spectrometry (XPS)}

Analysis of the samples was performed using a Thermo Scientific K-Alpha ESCA instrument equipped with aluminium Ka1,2 monochromatized radiation at $1486.6 \mathrm{eV}$ X-ray source. Due to the non conductor nature of samples it was necessary to use an electron flood gun to minimize surface charging. Neutralization of the surface charge was performed by using both a low energy flood gun (electrons in the range 0 to $14 \mathrm{eV}$ ) and an electrically grounded stain steel screen placed directly on the sample surface.

The XPS measurements were carried out using monochromatic Al-K radiation $(\mathrm{h} v=1486.6 \mathrm{eV})$. Photoelectrons were collected from a takeoff angle of $90^{\circ}$ relative to the sample surface. Measurements were done in a Constant Analyser Energy mode (CAE) with a $100 \mathrm{eV}$ pass energy for survey spectra and $20 \mathrm{eV}$ pass energy for high resolution spectra.

Charge referencing was done by setting the lower binding energy $\mathrm{C} 1 \mathrm{~s}$ photopeak at $285.0 \mathrm{eV} \mathrm{C} 1 s$ hydrocarbon peak. The spectra fitting was based on Chi-squared algorithm used to determine the goodness of a peak fit. Surface elemental composition was determined using the standard Scofield photoemission cross sections. The chemical functional groups identity was obtained from the high-resolution peak analysis of carbon-1s (C1s) and oxygen$1 \mathrm{~s}(\mathrm{O} 1 \mathrm{~s})$ envelopes.

\subsection{Time of flight secondary ion mass spectrometry (TOF -SIMS)}

The TOF-SIMS analyses were made on a TOF-SIMS IV (ION-TOF GmbH, Germany).The sample was bombarded with a pulsed Bismuth ion beam. The secondary ions generated were extracted with a $10 \mathrm{kV}$ voltage and their time of flight from the sample to the detector was measured in a reflectron mass spectrometer. Mass spectra of positive and negative secondary ions were acquired from randomly selected areas of $500 \times 500 \mu \mathrm{m}^{2}$ on each sample. In all 
cases, a $25 \mathrm{keV}$ pulsed $\mathrm{Bi}^{3+}$ beam at $45^{\circ}$ incidence was used. Low-energy electron flooding was used for charge compensation. All analyses were done under static SIMS conditions $\left(10^{12}\right.$ ions $\left./ \mathrm{cm}^{3}\right)$.

\subsection{Optic profilometry}

Interferometric profilometry measurements were carried out in the Vertical Scanning Interferometry (VSI) mode using an Interferometric Microscope WYKO NT-1100. For each sample, three measurements were carried out at a $5 \mathrm{X}$ magnification $\left(1.2 \times 0.9 \mathrm{~mm}^{2}\right)$, to determine statistically representative values of surface roughness parameters, and a measurement at magnifications of $20 \mathrm{X}$ $\left(298 \times 227 \mu \mathrm{m}^{2}\right)$ and $50 \mathrm{X}\left(119 \times 91 \mu \mathrm{m}^{2}\right)$ to see the details of the surface topography. Great field measurements covering an area of $3 \times 2 \mathrm{~mm}^{2}$ at a $5 \mathrm{X}$ magnification were also performed to obtain a more representative image of the surface.

\section{Results and discussion}

\subsection{Wettability of eucalyptus and ash wood veneers}

Figure 1 shows the evolution of contact angle with time for an aqueous solution of chestnut shell extracts on eucalyptus and ash veneers. For each species, veneers obtained from different positions in the trunk, interior and exterior, were compared. Throughout the time range tested, contact angles for eucalyptus veneers were significantly higher than those for ash veneers. Additionally, for both wood species there were not significant differences between the contact angles for the interior and exterior veneers.

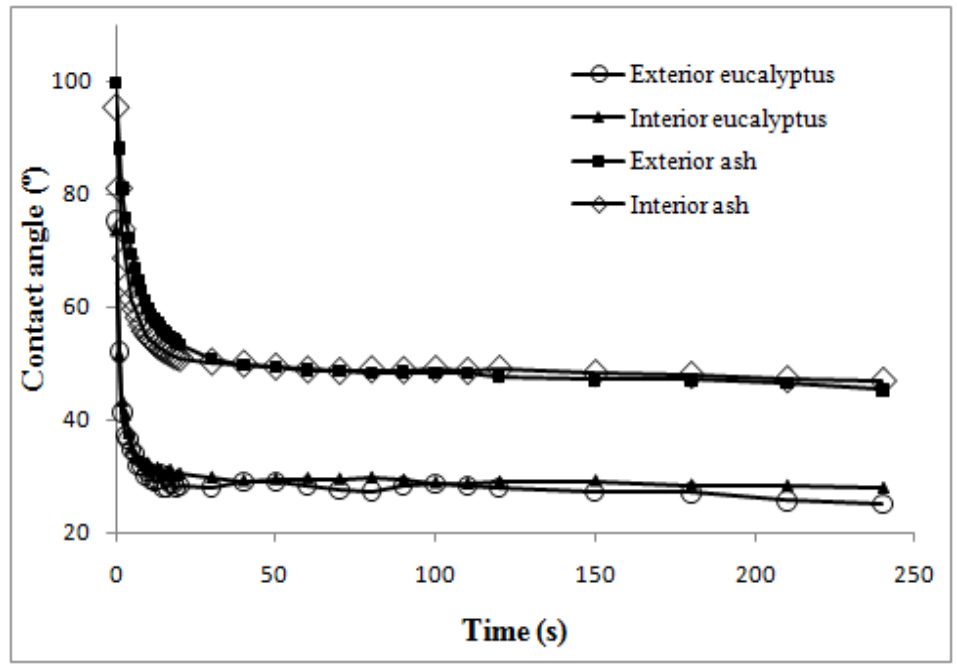

Figure 1: Contact angle versus time for an aqueous solution of chestnut shell extracts on interior and exterior eucalyptus and ash sliced veneers. 
The values calculated for the initial $\left(\mathrm{t}=0 ; \theta_{0}\right)$, final $\left(\mathrm{t}=240 \mathrm{~s} ; \theta_{\mathrm{f}}\right)$ and constant wetting rate (cwra) angles are presented in Table 1 . Not only initial contact angles but also final and constant wetting rate angles were remarkably higher for the eucalyptus veneers. Higher contact angles are indicative of a worse wetting behaviour and could be related with a greater migration of hydrophobic substances to the surface of eucalyptus veneers [7]. Differences between the $\theta_{0}$, $\theta_{\mathrm{f}}$ and cwra values of interior and exterior veneers were almost negligible which confirms the previous qualitative observation.

Table 1: Initial $\left(\theta_{0}\right)$, final $\left(\theta_{\mathrm{f}}\right)$ and constant wetting rate (cwra) angles for exterior and interior veneers of eucalyptus and ash wood with an aqueous solution of chestnut shell extracts.

\begin{tabular}{|c|c|c|c|c|c|c|}
\hline \multirow{2}{*}{ Veneer } & \multicolumn{3}{|c|}{ Exterior } & \multicolumn{3}{|c|}{ Interior } \\
\hline & $\theta_{0}\left({ }^{0}\right)$ & $\theta_{\mathrm{f}}\left({ }^{0}\right)$ & $\operatorname{cwra}\left({ }^{\circ}\right)$ & $\theta_{0}\left(^{0}\right)$ & $\theta_{\mathrm{f}}\left({ }^{\circ}\right)$ & $\operatorname{cwra}\left({ }^{\circ}\right)$ \\
\hline Eucalyptus & $\begin{array}{l}99.72 \\
(5.83)\end{array}$ & $\begin{array}{l}45.25 \\
(1.88)\end{array}$ & $\begin{array}{c}50.8 \\
(0.11)\end{array}$ & $\begin{array}{l}95.34 \\
(4.77)\end{array}$ & $\begin{array}{l}46.70 \\
(6.77)\end{array}$ & $\begin{array}{l}50.12 \\
(0.10)\end{array}$ \\
\hline Ash & $\begin{array}{l}75.22 \\
(1.44)\end{array}$ & $\begin{array}{l}28.01 \\
(0.37)\end{array}$ & $\begin{array}{l}27.99 \\
(0.37)\end{array}$ & $\begin{array}{l}73.42 \\
(9.91)\end{array}$ & $\begin{array}{l}27.75 \\
(8.43)\end{array}$ & $\begin{array}{c}30.6 \\
(0.76)\end{array}$ \\
\hline
\end{tabular}

(Standard deviation)

\subsection{X-ray photoelectron spectrometry (XPS)}

Figure 2a shows the XPS survey spectra of eucalyptus and ash samples of interior veneers. The surface elemental compositions (in atomic \%) for the different sample groups are summarized in Table 2. The percentages shown are the mean value of three determinations.

Table 2: $\quad$ Surface elemental composition (in atomic \%) for eucalyptus and ash veneers.

\begin{tabular}{|c|c|c|c|c|c|}
\hline Veneer & $\mathbf{C}$ & $\mathbf{O}$ & $\mathbf{N}$ & $\mathbf{S i}$ & $\mathbf{C a}$ \\
\hline Exterior & 80.7 & 18.0 & 0.7 & 0.6 & - \\
eucalyptus & $(2.2)$ & $(2.3)$ & $(0.2)$ & $(0.1)$ & \\
\hline Interior & 79.2 & 19.3 & 1.0 & 0.8 & - \\
eucalyptus & $(0.1)$ & $(0.7)$ & $(0.4)$ & $(0.2)$ & \\
\hline \multirow{2}{*}{ Exterior ash } & 77.2 & 20.8 & 0.6 & 1.2 & 0.3 \\
& $(1.0)$ & $(1.1)$ & $(0.1)$ & $(0.5)$ & $(0.1)$ \\
\hline \multirow{2}{*}{ Interior ash } & 76.9 & 20.5 & 0.9 & 1.2 & 0.5 \\
& $(1.4)$ & $(1.2)$ & $(0.1)$ & $(0.5)$ & $(0.1)$ \\
\hline
\end{tabular}

(Standard deviation)

As seen in Table 2, carbon and oxygen are the main components in the wood surfaces and small amounts of nitrogen and silicon were also detected in both wood species, whereas calcium was present only in the ash samples.

Nitrogen is present in the form of amine/amide functional groups. This assignment is as a result of the N1s peak position, which is at approximately 400 
$\mathrm{eV}$ (with $\mathrm{C}-\mathrm{C}$ carbon set at $285.0 \mathrm{eV}$ as the binding energy scale reference). The presence of such compounds is mainly as a result of naturally occurring proteins in wood but some contamination by adsorption from the laboratory air cannot be excluded [8].

From the high resolution spectra (Figure $2 \mathrm{~b}$ ) the functional groups which made up the C1s spectra have been identified. The C1s spectra of all samples comprised four peaks with binding energies (BE) of approximately $285.0(\mathrm{C} 1)$, $286.6(\mathrm{C} 2), 288.1(\mathrm{C} 3)$ and $289.2(\mathrm{C} 4) \mathrm{eV}$. The $\mathrm{C} 1$ carbon component is related to $\mathrm{C}-\mathrm{C}$ or $\mathrm{C}-\mathrm{H}$ bonds, the $\mathrm{C} 2$ carbon component represents single $\mathrm{C}-\mathrm{O}$ bonds, the $\mathrm{C} 3$ carbon component is bonded to a carbonyl or two non-carbonyl oxygen $(\mathrm{C}=\mathrm{O}$ or $\mathrm{O}-\mathrm{C}-\mathrm{O})$ and the $\mathrm{C} 4$ class of carbon atoms is bonded to a carbonyl and a non-carbonyl oxygen $(\mathrm{O}=\mathrm{C}-\mathrm{O})[9]$.
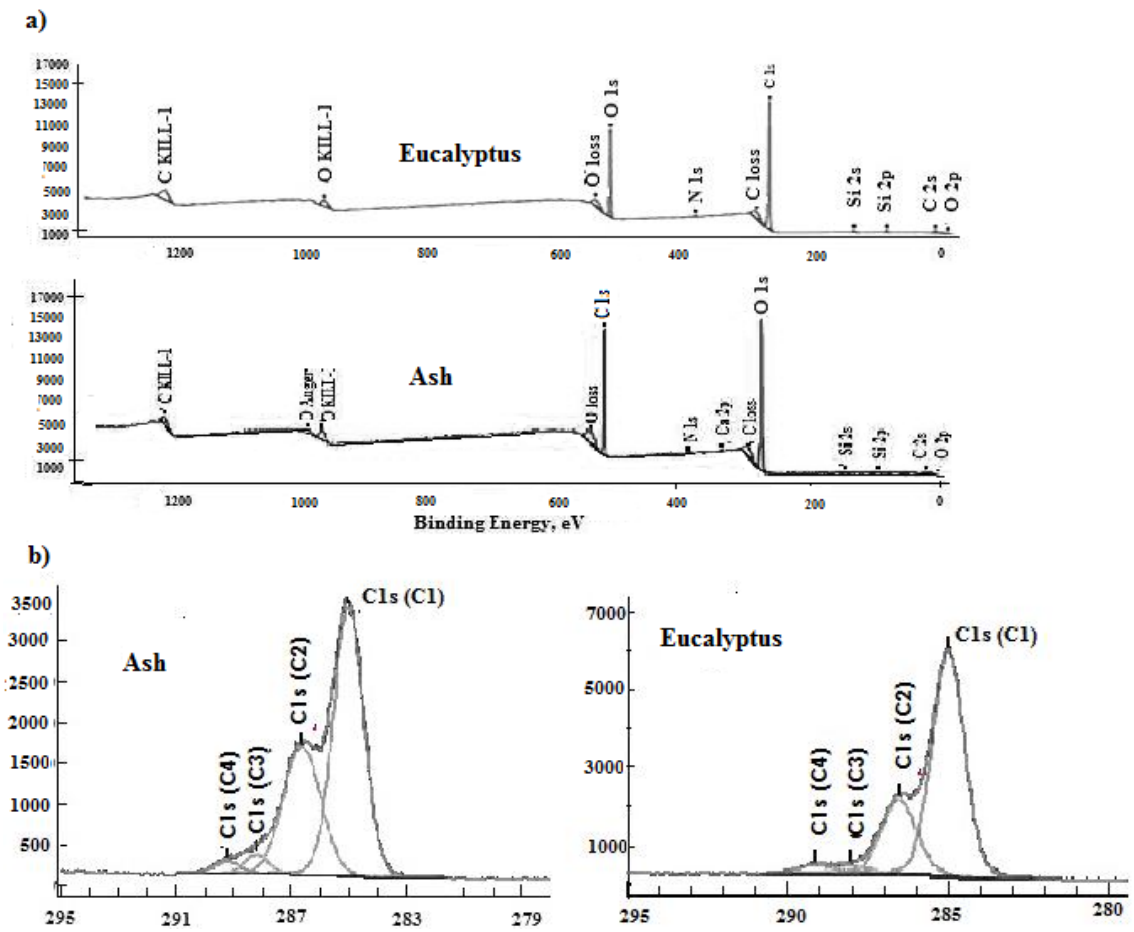

Figure 2: XPS survey spectra (a) and high resolution C1s spectra (b) for interior eucalyptus and ash veneers.

The relative percentages of the $\mathrm{C} 1 \mathrm{~s}$ components are shown in Table 3 together with the $\mathrm{O} / \mathrm{C}$ and $\mathrm{C} 1 / \mathrm{C} 2$ ratios. The $\mathrm{C} 1$ component arises from lignin and extractives and the $\mathrm{C} 2$ component can arise from all wood components but predominantly from cellulose. For both species, most carbon atoms (60-66.5\%) present in the wood surface layer were C1-carbons, and between 29.2 and 33.5\% of the total carbon signal was from the $\mathrm{C} 2$ type. According to a normal wood 
composition and the structure of wood components, carbon atoms bonded with one oxygen atom ( $\mathrm{C} 2$ component) should be greater. The observed increase in the presence of $\mathrm{C} 1$ components, which was more significant for eucalyptus samples, might be due to the migration of lipophilic extractives to the wood surface [9].

Table 3: Percentages of the $\mathrm{C} 1 \mathrm{~s}$ spectra components and $\mathrm{C} 1 / \mathrm{C} 2$ and $\mathrm{O} / \mathrm{C}$ ratios for eucalyptus and ash veneers.

\begin{tabular}{|c|c|c|c|c|c|c|}
\hline Veneer & $\mathbf{C 1}$ & $\mathbf{C 2}$ & $\mathbf{C 3}$ & $\mathbf{C 4}$ & $\mathbf{C 1 / C 2}$ & $\mathbf{O} / \mathbf{C}$ \\
\hline $\begin{array}{c}\text { Exterior } \\
\text { eucalyptus }\end{array}$ & $\begin{array}{c}66.5 \\
(4.7)\end{array}$ & $\begin{array}{c}29.2 \\
(3.4)\end{array}$ & $\begin{array}{c}2.3 \\
(1.6)\end{array}$ & $\begin{array}{c}2.0 \\
(0.4)\end{array}$ & 2.3 & 0.22 \\
\hline $\begin{array}{c}\text { Interior } \\
\text { eucalyptus }\end{array}$ & $\begin{array}{c}65.4 \\
(2.9)\end{array}$ & $\begin{array}{c}29.3 \\
(3.2)\end{array}$ & $\begin{array}{c}2.8 \\
(0.5)\end{array}$ & $\begin{array}{c}2.8 \\
(0.3)\end{array}$ & 2.2 & 0.24 \\
\hline Exterior ash & $\begin{array}{c}60.1 \\
(1.7)\end{array}$ & $\begin{array}{c}32.4 \\
(0.4)\end{array}$ & $\begin{array}{c}5.0 \\
(1.2)\end{array}$ & $\begin{array}{c}2.6 \\
(0.1)\end{array}$ & 1.9 & 0.27 \\
\hline Interior ash & $\begin{array}{c}60.0 \\
(2.2)\end{array}$ & $\begin{array}{c}33.5 \\
(2.4)\end{array}$ & $\begin{array}{c}4.1 \\
(1.0)\end{array}$ & $\begin{array}{c}2.4 \\
(0.7)\end{array}$ & \multirow{2}{*}{1.8} & 0.27 \\
\hline
\end{tabular}

(Standard deviation)

This theory is reinforced by the values obtained for the $\mathrm{O} / \mathrm{C}$ and $\mathrm{C} 1 / \mathrm{C} 2$ ratios, which are directly related to the chemical composition of wood constituents (polysaccharides, lignin and extractives). The $\mathrm{O} / \mathrm{C}$ ratio varied between 0.22 and 0.27 (Table 3). If experimental $\mathrm{O} / \mathrm{C}$ ratio values are compared to those of pure compounds, 0.83 for cellulose, 0.33 for lignin and 0.1 for extractives [10] the preferential presence of lignin and extractives on the wood surface is demonstrated, mainly in the case of eucalyptus veneers. Moreover, the $\mathrm{C} 1 / \mathrm{C} 2$ ratio provides an additional evidence to support the above interpretations. Theoretically calculated values for the $\mathrm{C} 1 / \mathrm{C} 2$ ratio are equal to 0 for pure cellulose, around 1 for lignin and 10 or higher for extractives [11]. Therefore, values in the range from 1.8 to 2.3 confirm the presence of extractives on the wood surfaces and especially on eucalyptus wood.

Finally, when comparing the mean values of the $\mathrm{C} 1 / \mathrm{C} 2$ and $\mathrm{O} / \mathrm{C}$ ratios and the C1-carbon percentages, more hydrophobic material was found in exterior eucalyptus veneers. The more hydrophobic character of the eucalyptus wood samples is in agreement with the results obtained from contact angle measurements which revealed better wetting properties for ash veneers.

\subsection{Time of flight secondary ion mass spectrometry (TOF-SIMS)}

TOF-SIMS spectra were prepared to represent the masses from 1 to $700 \mathrm{u}$, although the range from 100 to $200 \mathrm{u}$ is the most interesting because in this spectral region fragments of lignin and carbohydrates are detected. On the contrary, in the region below $100 \mathrm{u}$, multiple fragments which are common to all organic materials, the so-called non-specific organic fragments appear and, therefore, fragments of this region of the spectrum are rarely used in the study of 
organic compounds. $\mathrm{Na}, \mathrm{Ca}$ or $\mathrm{Al}$, are also detected in the area of the spectrum below $100 \mathrm{u}$. However, the intensity of these ions is low when compared with the intensity of the peaks of hydrocarbons. Extractive organic compounds appear in areas of the spectrum with $\mathrm{m} / \mathrm{z}$ values between 230 and $700 \mathrm{u}$.

Figure 3 shows the comparative positive polarity spectra for ash and eucalyptus veneers at $\mathrm{m} / \mathrm{z}$ values from 135 to $185 \mathrm{u}$. Negative polarity spectra were nor included due to the low intensity of the observed signals. For both samples, the characteristic ions of lignin, at $\mathrm{m} / \mathrm{z}=137$ and 151 for lignin guaiacyl units $(\mathrm{G})$, and at $\mathrm{m} / \mathrm{z}=167$ and 181 for lignin syringyl units (S), were observed.

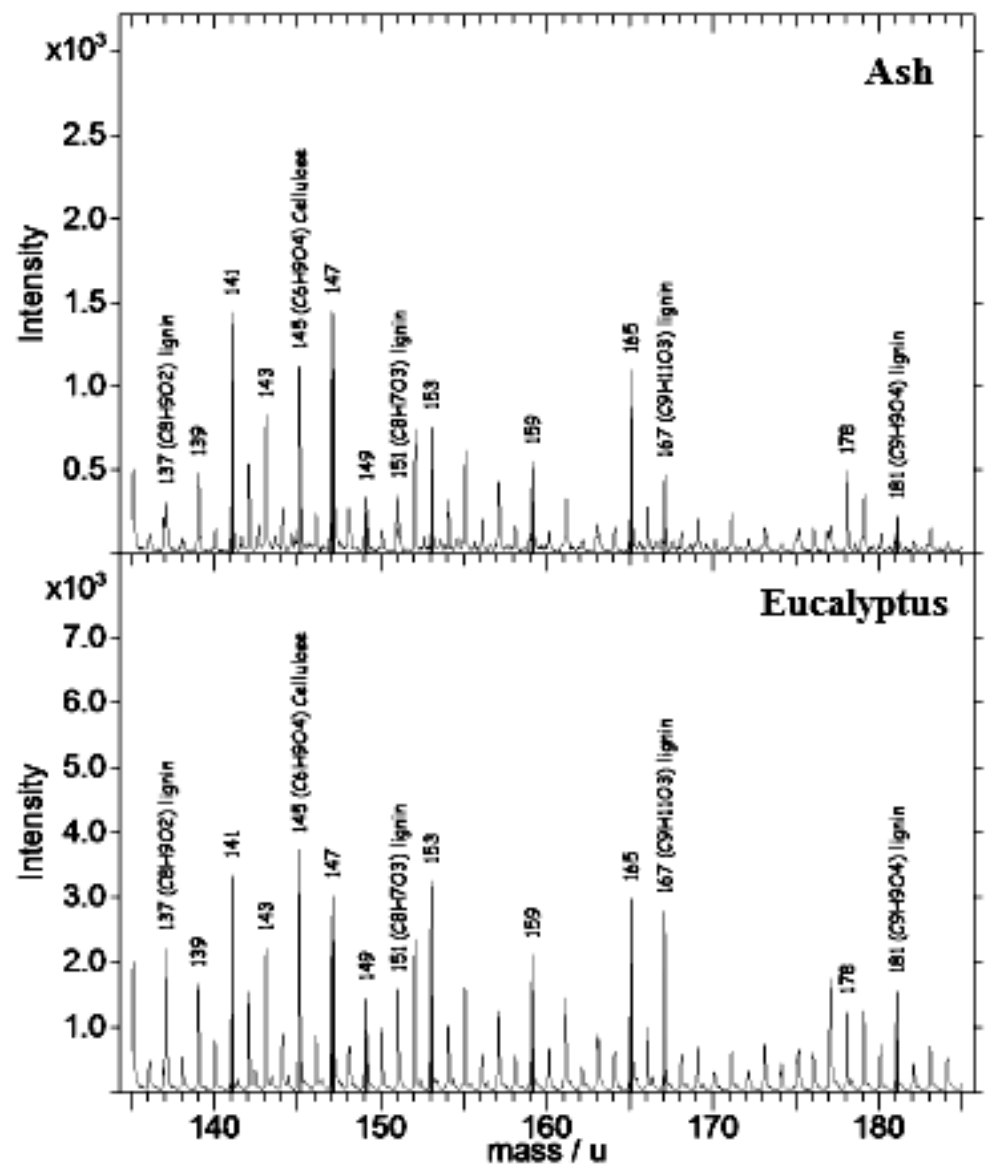

Figure 3: Comparison of the positive ion TOF-SIMS spectra from 135 to 185 $\mathrm{u}$ for eucalyptus and ash veneers.

Typical peaks of cellulose and hemicelluloses, localized at $\mathrm{m} / \mathrm{z}=115,127$, 133 and $145 \mathrm{u}$, also appeared. Peaks at $\mathrm{m} / \mathrm{z}=115$ and $133 \mathrm{u}$ are attributed to xylan, the peak at $127 \mathrm{u}$ to mannan and the one at $145 \mathrm{u}$ to cellulose. Additional peaks at $\mathrm{m} / \mathrm{z}=147$ and $149 \mathrm{u}$ are attributed to mannan and cellulose. 
TOF-SIMS technique is not quantitative and, therefore, direct comparison of the intensity of a particular ion in different samples does not allow extracting conclusions about its abundance. However, it is possible to compare different samples by referring the intensities of the ions of interest to that of another ion not related to them. In this way, the intensities of the lignin ions at $\mathrm{m} / \mathrm{z}=137$, 151,167 and $181 \mathrm{u}$ in eucalyptus and ash wood samples were referred to that of the ion at $\mathrm{m} / \mathrm{z}=147 \mathrm{u}$, attributable to hemicelluloses and present in both kind of samples. The relative intensity of lignin ions in eucalyptus samples was slightly higher than in the ash ones, which indicated that lignin was more abundant on the eucalyptus veneer surfaces.

Figure 4 presents the comparison of the positive polarity TOF-SIMS spectra for eucalyptus and ash veneers in the region from 135 to $450 \mathrm{u}$. Signals at 383, 397 and $425 \mathrm{u}$ are attributed to organic wood extractives. As shown in the spectra, the content of extractives is higher in the eucalyptus sample than in the ash one which is consistent with XPS results.

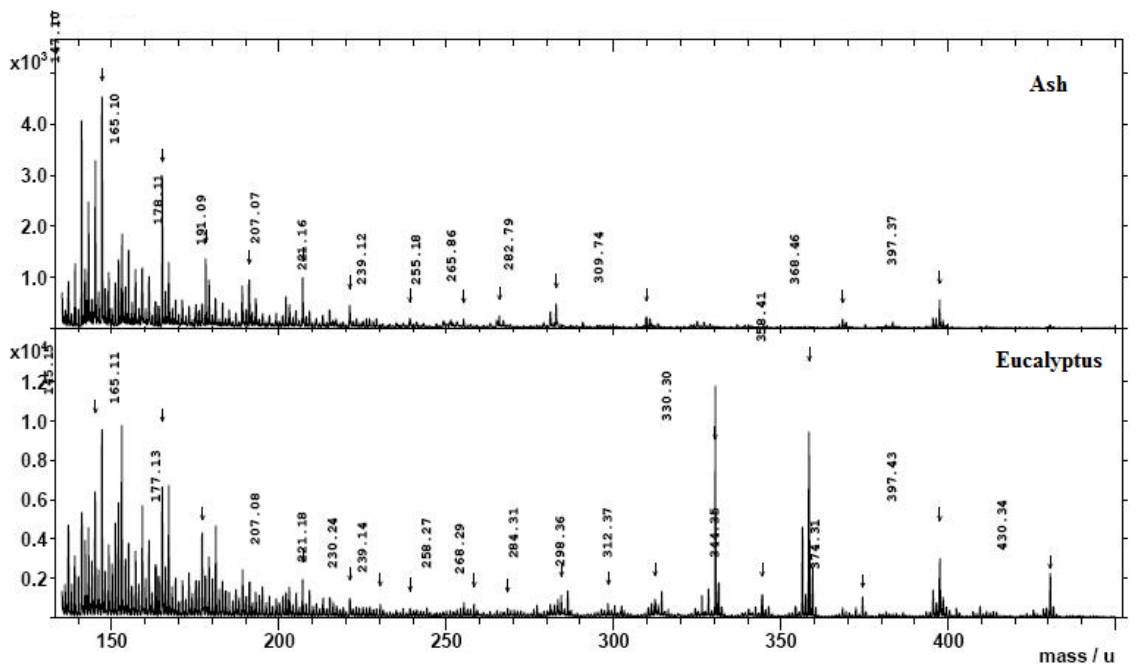

Figure 4: $\quad$ Comparison of the positive ion TOF-SIMS spectra from 135 to 450 $\mathrm{u}$ for eucalyptus and ash veneers.

Positive ion images for selected ions signals from eucalyptus and ash samples are shown in Figure 5. Black colour indicates no ion signal and white colour maximum signal intensity. Images of all the characteristic ions for lignin (137, $151,167$ and $181 \mathrm{u})$ and extractives, mainly sterols $(383,397$ and $425 \mathrm{u}$ ), are presented together. Ion images showed that lignin and mainly extractives were more prominent on eucalyptus than on ash veneer surfaces and, moreover, revealed that both components were inhomogeneously distributed on the surface. 
a)

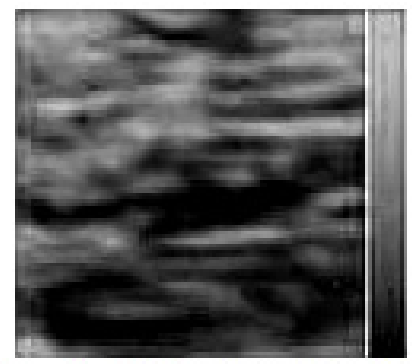

Lignin $(137+151+167+181)$

b)

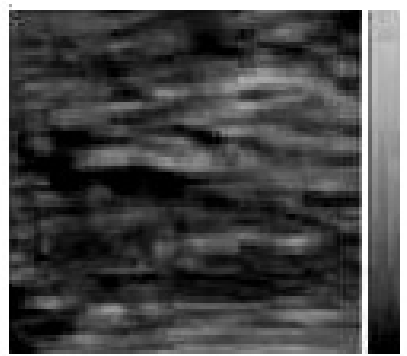

Lignin $(137+167+181)$

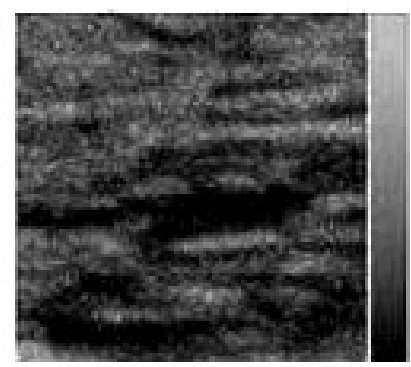

Sterols $(383+397+425)$

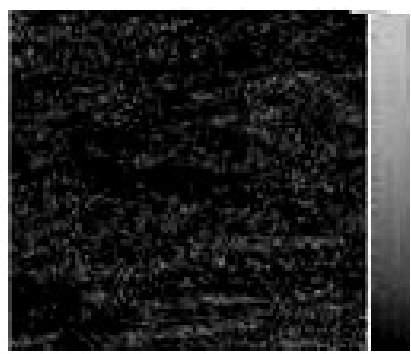

Sterols (383+397+425)

Figure 5: $\quad$ Positive ion images for eucalyptus (a) and ash (b) samples.

\subsection{Optic profilometry}

Table 4 shows the average values of the roughness parameters Ra (arithmetic mean of the absolute value of the distances from the mean line to the profile) and $\mathrm{Rq}$ (mean value of the square roots of the distances from the mean line to the profile) for eucalyptus and ash veneer samples. Due to the heterogeneity of wood samples, surface roughness values depended strongly on the topographic characteristics of each particular area, so that the values showed a high dispersion. Therefore, the most representative roughness values might be those of the larger areas (called stitch), as the measure itself represents the average of a larger area of the samples.

The main conclusion drawn from the values of surface roughness is that ash samples are rougher than eucalyptus samples, approximately 1.7 times based on the results of the stitch areas, which can be related with the better wettability behaviour previously encountered. 
Table 4: $\quad$ Roughness average values for eucalyptus and ash veneer surfaces.

\begin{tabular}{|c|c|c|c|}
\hline Sample & Magnification & $\mathbf{R a}(\mu \mathbf{m})$ & $\mathbf{R q}(\mu \mathbf{m})$ \\
\hline \multirow{4}{*}{ Eucalyptus } & $5 \mathrm{X}\left(1.2 \mathrm{x} 0.9 \mathrm{~mm}^{2}\right)$ & $\begin{array}{l}11.31 \\
(2.44)\end{array}$ & $\begin{array}{l}16.26 \\
(4.63)\end{array}$ \\
\hline & $20 \mathrm{X}\left(298 \times 227 \mu \mathrm{m}^{2}\right)$ & $\begin{array}{c}3.44 \\
(1.24)\end{array}$ & $\begin{array}{c}5.11 \\
(0.66)\end{array}$ \\
\hline & $50 \mathrm{X}\left(119 \times 91 \mu \mathrm{m}^{2}\right)$ & $\begin{array}{c}2.30 \\
(0.91)\end{array}$ & $\begin{array}{c}2.93 \\
(1.00)\end{array}$ \\
\hline & STITCH $\left(3 \times 2 \mathrm{~mm}^{2}\right)$ & $\begin{array}{l}15.91 \\
(0.45)\end{array}$ & $\begin{array}{l}23.56 \\
(4.70)\end{array}$ \\
\hline \multirow{4}{*}{ Ash } & $5 \mathrm{X}\left(1.2 \mathrm{x} 0.9 \mathrm{~mm}^{2}\right)$ & $\begin{array}{l}12.17 \\
(1.23)\end{array}$ & $\begin{array}{l}15.92 \\
(1.23)\end{array}$ \\
\hline & $20 \mathrm{X}\left(298 \times 227 \mu \mathrm{m}^{2}\right)$ & $\begin{array}{c}8.78 \\
(2.60)\end{array}$ & $\begin{array}{l}11.61 \\
(4.14)\end{array}$ \\
\hline & $50 \mathrm{X}\left(119 \times 91 \mu \mathrm{m}^{2}\right)$ & $\begin{array}{c}6.10 \\
(2.56)\end{array}$ & $\begin{array}{c}8.05 \\
(3.54)\end{array}$ \\
\hline & STITCH (3x2 mm²) & $\begin{array}{l}27.38 \\
(2.55)\end{array}$ & $\begin{array}{l}39.36 \\
(6.80)\end{array}$ \\
\hline
\end{tabular}

(Standard deviation)

\section{Acknowledgements}

This work was funded by Ministerio de Ciencia e Innovación, FEDER Funds and Plan E Fundy (CTQ2009-07539).

\section{References}

[1] Bryne, L.E. \& Walinder, M.E.P., Ageing of modified wood. Part 1: Wetting properties of acetylated, furfurylated, and thermally modified wood. Holzforschung, 64, pp. 295-304, 2010.

[2] Englund F., Bryne L.E., Ernstsson M., Lausmaa J. \& Walinder M., Spectroscopic studies of surface chemical composition and wettability of modified wood. Wood Mater. Sci. Eng., 1-2, pp. 80-85, 2009.

[3] Bryne, L.O., Lausmaa, J., Ernstsson, M., Englund, F. \& Walinder, M.E.P., Ageing of modified wood. Part 2: Determination of surface composition of acetylated, furfurylated, and thermally modified wood by XPS and ToFSIMS. Holzforschung, 64, pp. 305-313, 2010.

[4] Tokareva, E.N., Fardim, P., Pranovich, A.V., Fagerholm, H.P., Daniel, G. \& Holmbom, B., Imaging of wood tissue by ToF-SIMS: Critical evaluation and development of sample preparation techniques. App. Surf. Sci., 253, pp. 7569-7577, 2007.

[5] Vázquez, G., González-Alvarez, J., Santos, J., Freire, M.S. \& Antorrena, G., Evaluation of potential applications for chestnut (Castanea sativa) shell 
and eucalyptus (Eucalyptus globulus) bark extracts. Ind. Crops Prod., 29, pp. 364-370, 2009.

[6] Nussbaum, R.M., Natural surface inactivation of Scots pine and Norway spruce evaluated by contact angle measurements. Holz Roh-Werkstoff, 57, pp. 419-424, 1999.

[7] Christiansen, A.W., Effect of ovendrying of yellow-poplar veneer on physical properties and bonding. Holz Roh-Werkstof , 52, pp. 139-149, 1994

[8] Popescu, C.N, Tibirna, C.N. \& Vasile C., XPS characterization of naturally aged wood, App. Surf. Sci., 256, pp. 1355-1360, 2009.

[9] Sinn, G., Reiterer, A. \& Stanzl-Tschegg, S.E., Surface analysis of different wood species using X-ray photoelectron spectroscopy (XPS). J. Mater. Sci., 36, pp. 4673-4680, 2001.

[10] Barry, A.O., Koran, Z. \& Kaliaguine, S., Surface analysis by ESCA of sulfite post-treated CTMP. J. Applied Polym. Sci., 39, pp. 31-42, 1990.

[11] Sernek, M., Kamke1, F.A. \& Glasser, W.G., Comparative analysis of inactivated wood surface, Holzforschung, 58, pp. 22-31, 2004. 